\title{
Métodos de secagem e rendimento dos extratos de folhas de Plectranthus barbatus (boldo-da-terra) e P. ornatus (boldo-miúdo)
}

\author{
RODRIGUES,T.S.'; GUIMARÃES,S.F.1; *RODRIGUES-DAS-DÔRES, R.G.'; GABRIEL,J.V.1 \\ ${ }^{1}$ Centro de Saúde/Universidade Federal de Ouro Preto, Campus Universitário - Morro do Cruzeiro, 35400-000: \\ Ouro Preto, Brasil. * rosanagrd@hotmail.com
}

\begin{abstract}
RESUMO: Plectranthus sp. pertence à família Lamiaceae e inclui cerca de 300 espécies. Duas delas, $P$. barbatus (PB) e P. ornatus (PO) destacam-se pelo interesse medicinal. As principais substâncias encontradas em Plectranthus sp. são os diterpenóides, óleos essenciais e compostos fenólicos. A melhor forma de utilizar as folhas de PB e PO é a fresco; porém, na comercialização há necessidade de recorrer a processos de secagem. Entretanto, isto pode interferir no princípio ativo, desta forma, estudos para determinar o melhor método gravimétrico são importantes. $O$ objetivo deste estudo foi avaliar qual o melhor método de secagem, onde haja maior perda de água possível, e calcular os rendimentos dos extratos visando avaliar se o método gravimétrico interfere na quantidade de extrato produzido. Desta forma, utilizou-se quatro métodos de secagem e após evaporação do solvente, fez-se o cálculo do rendimento dos extratos secos. O percentual de água foi superior em PB e PO (média geral de 90,12 $\pm 8,22 \%$ ). Dentre as secagens, em estufa de ventilação forçada (EVF) foi mais eficiente em PB $(88,87 \%)$ e em estufa convencional (ECO) foi melhor em PO (95,13\%). O maior rendimento do extrato seco em PB foi na secagem em camada delgada (CD) (20,96\%), enquanto que em PO foi ECO (41,34\%). Não houve correlação entre o método de secagem e o rendimento de extrato obtido.
\end{abstract}

Palavras-chave: Boldos-do-Brasil, gravimetria, pós-colheita

\begin{abstract}
Methods estimated drying and percentage of extracts in leaves of Plectranthus barbatus (Brazilian bold) and $\boldsymbol{P}$. ornatus (false bold). Plectranthus $s p$. belongs to the family Lamiaceae and includes about 300 species. Two of them, P. barbatus (PB) and P. ornatus (PO), have medicinal interest. The main substances found in Plectranthus $s p$. are the diterpenoids, essential oils and phenolic compounds. The best way to use the leaves of PB and PO is cool; but for marketing there is a need of resort to drying processes. However, this may interfere on the values of active principle; thus, studies to determine the best gravimetric methods are important. The objective of this study was to evaluate the best method of drying, where there the greater loss of water possible, and calculate the percentage of the extracts to assess whether the gravimetric method interferes with the amount of extract produced. To this was done by drying four different methods ventilated dry (EVF), conventional drying (ECO), microwave (MCO) and layer thing (CD) and after evaporation of the solvent, was made the calculation the percentage of the dried extract. The water content was higher in PB and PO (overall average of $90.12 \pm 8.22 \%$ ). Among the drying, EVF was more efficient for PB (88.87\%) and ECO was better for PO (95.13\%). The highest content of dry extract was for PB in to CD $(20.96 \%)$, whereas for PO was in to ECO $(41.34 \%)$. There is no relationship between the drying method and in the quantity of extract obtained.
\end{abstract}

Key words: Brazilian Bolds, gravimetry, post-harvesting.

\section{INTRODUÇÃO}

Plectranthus sp. pertence à família Lamiaceae (sinonímia Labiateae) e inclui cerca de 300 espécies, as quais estão distribuídas na África Tropical, Ásia e Austrália (LUKHOBA, 2006). Algumas espécies desse gênero foram introduzidas no Brasil e se adaptaram. As espécies de Plectranthus sp. têm interesse econômico, podendo ser utilizadas como ornamentais, como por exemplo, P. tenuiflorus.

Recebido para publicação: agosto de 2011

Aceito para publicação: dezembro de 2011

Rev. Bras. PI. Med., Botucatu, v.13, especial, p.587-590, 2011. 
(LUKHOBA, 2006). Porém, destaca-se o uso medicinal de muitas espécies desse gênero, incluindo as referidas neste artigo: $P$. barbatus e P.ornatus. Sabe-se que os principais compostos com possíveis propriedades medicinais encontrados em Plectranthus $s p$. são os diterpenóides, óleos essenciais e compostos fenólicos (ABDEL-MOGIB, 2002).

$P$. barbatus Andrews é espécie popularmente conhecida como boldo-peludo, falso-boldo, boldobrasileiro, alumã dentre outros (LORENZI et al., 2008). Na medicina popular é indicada em cólica abdominal (DUBEY et al., 1981); como purgativo, no tratamento de gastrites, espamos intestinais, doenças hepáticas e dentárias (LUKHOBA et al., 2006); na asmas, bronquites, pneumonias e outras doenças respiratórias (LUKHOBA et al., 2006; YANG et al., 2006).

$P$. ornatus Codd. é popularmente conhecido como boldo-miúdo, boldo-gambá, boldo-do-Chile dentre outros nomes. Possui propriedades medicinais semelhantes à $P$. barbatus, destacando-se na medicina popular. As pesquisas com $P$. ornatus tornam-se importantes devido à equivalência entre eles, além da espécie ser pouco estudada. P. ornatus é citado também por suas propriedades analgésicas e diuréticas (CORRÊA et al., 1998) e por diminuir a secreção gástrica (DELLAR et al., 1996).

Sabe-se que o modo de uso, mais prevalente, pela população de plantas medicinais é da erva fresca ou in natura, pois se acredita que assim há garantia de que todos os compostos responsáveis pelo efeito estarão presentes. Contudo, a estocagem e comercialização in natura destas espécies tornamse inviáveis, pois a planta fresca possui alto teor de água, o que facilita a proliferação de microrganismos e as reações enzimáticas que podem provocar sua deterioração ou até mesmo degradação do princípio ativo. Buscando solucionar tal problema, testou-se métodos gravimétricos de secagem natural e artificial. Contudo, definir o melhor tipo de secagem é complicado, pois a metodologia ideal deve ser aquela que promova a maior porcentagem de perda de água e não altere o princípio ativo. Desta forma, o objetivo deste estudo foi avaliar o melhor método de secagem de folhas de $P$. barbatus e $P$. ornatus e calcular 0 rendimento dos extratos nos tratamentos, avaliando se o tipo de secagem influencia na quantidade de extrato produzido.

\section{MATERIAL E MÉTODO}

\section{Material vegetal}

Aproximadamente $3,0 \mathrm{~kg}$ de folhas totalmente expandidas foram colhidas manualmente, do terço mediano de plantas adultas de $P$. barbatus e $P$. ornatus, no mês de maio de 2010, no horto medicinal da Universidade Federal de Ouro Preto (UFOP), Ouro Preto, Minas Gerais, Brasil (coordenadas 2023'47.36" S; 4330’35.51" O). Após a colheita, selecionaram-se as folhas, e submetendo-as ao processamento vegetal. Estruturas propagativas e vegetativas de $P$. barbatus e $P$. ornatus colhidas no horto medicinal foram identificadas pela Dra. Viviane R. Scalon, taxonomista e curadora do Herbário Professor José Badini da UFOP. Exsicatas de $P$. barbatus e $P$. ornatus originárias do mesmo material, estão depositadas no herbário, sob os números OUPR12671 e OUPR7043 para $P$. barbatus e $P$. ornatus, respectivamente. Material-testemunho encontra-se cultivado no Centro de Saúde da UFOP.

\section{Gravimetria}

As análises da porcentagem de perda de água das folhas de $P$. barbatus (PB) e $P$. ornatus (PO) seguiram os padrões descritos no tópico "Determinação da Perda por Dessecação" da Farmacopéia Brasileira V (2010), com algumas modificações. Na determinação do melhor método gravimétrico, foram feitos quatro tipos de secagem: estufa convencional (ECO), estufa de ventilação forçada (EVF), camada delgada (CD) e microondas (MCO). Em cada tratamento de secagem, pesou-se aproximadamente $20,0 \mathrm{~g}$ de folhas de PB e PO, divididos em quatro repetições de $5,0 \mathrm{~g}$ cada uma.

Nos tratamentos em ECO e EVF (ambas da marca TECNAL $®$ ), as repetições foram colocadas em pesa-filtros, previamente tarado e dessecado por cerca de 30 minutos a temperatura de $105^{\circ} \mathrm{C}$. Colocou-se o material vegetal em EVF e ECO, pré-aquecida, em temperatura de $105^{\circ} \mathrm{C}$ na secagem em EVF e $40^{\circ} \mathrm{C}$ em ECO, por 5 horas. Retirou-se este material da estufa de ventilação forçada, resfriou-o em dessecador por 1 hora à temperatura ambiente e pesou-se. $O$ processo foi repetido até que atingisse o peso constante (FARM. BRAS. V, 2010), no qual teve uma duração de 17 dias tanto em ECO quanto em EVF, e nas duas espécies de boldo.

No método gravimétrico de dessecação em $\mathrm{CD}$, o material foi pesado em papéis-filtro previamente tarados e colocado entre dois papéis-filtro circulares, com diâmetro de aproximadamente $20 \mathrm{~cm}$, e mantidos a temperatura ambiente $\left( \pm 25^{\circ} \mathrm{C}\right)$. As repetições atingiram peso constante após 65 dias. A secagem em MCO (marca Eletrolux, modelo ME18S), realizada em tempo total de 12 minutos, foi feita em béqueres de vidro de $50 \mathrm{~mL}$ e usando a potência máxima do aparelho (100\%). As folhas de PB e PO foram colocadas para secar, em intervalos de 30 em 30 segundos, resfriadas e pesadas. Repetiu-se 0 procedimento até peso constante.

Preparação dos extratos

Os extratos de folhas frescas (FRE), secas

Rev. Bras. Pl. Med., Botucatu, v.13, especial, p.587-590, 2011. 
em ECO, EVF, CD e MCO foram preparados por maceração em Etanol PA. Em cada 20,0g de folhas, utilizou-se cerca de $100 \mathrm{~mL}$ do solvente, procedendose, em seguida a filtração do extrato e evaporação em evaporador rotativo, obtendo o extrato seco. Calculou-se o rendimento total dos extratos, de acordo com a fórmula: $R e=($ Pext $/$ Pfolhas $) \times 100$.

Onde: $\mathrm{Re}=$ Rendimento total do extrato (\%); Pext $=$ Peso do extrato seco (g); Pfolhas = Peso das folhas frescas ou secas $(\mathrm{g})$.

\section{Análises estatísticas}

Nos cálculos dos índices de massa seca, massa fresca e percentagem de perda de água, fezse uso do programa SAEG for Windows (UFV, 20010. Os resultados foram submetidos à análise de variância e teste de média (Tukey) a $5 \%$ de significância.

\section{RESULTADO E DISCUSSÃO}

O resumo da análise de variância e analise da média dos quatro tratamentos estão dispostos nas tabelas 1 e 2. As médias gerais em massa fresca (MF), massa seca (MS) e teor de água (TA) das folhas de PB e PO foram 5,14 $\pm 0,14 \mathrm{~g}, 0,51 \pm 0,19 \mathrm{~g}$ e $90,12 \pm 8,22 \%$, respectivamente. As médias de MS e
PPA demonstraram que a perda de água foi consideravelmente alta em ambas as espécies, o que denota os seus elevados teores de água. No entanto, PO teve em média maior PPA que PB (Tabela 2); isso se deve ao fato das folhas desta espécie serem mais suculentas, indicando a maior teor de água reservada nos vacúolos dos tecidos.

As médias dos teores de MF, MS e TA em função do tratamento estão dispostos na tabela 2. Percebe-se que as médias de massa fresca não tiveram diferenças significativas, tendo apenas variado em PB seco em CD e COM, o que era esperado, uma vez que fez-se a pesagem de folhas integras, previamente selecionadas por tamanho, para constituir os tratamentos suas repetições que foram pesados com valores aproximados (cerca de 5,0g).

Os valores das médias comprovam que em PB o método de secagem onde há maior perda no teor de água foi EVF (88,87\%), enquanto que em PO foi ECO (95,13\%), não havendo diferença significativa em relação à secagem em EVF (Tabela 2). Entretanto, baseando-se em análise sensorial, considerou-se o método gravimétrico EVF mais indicado, por causar menores danos ao material vegetal, causando menor alteração nos caracteres organolépticos e nos compostos secundários e

TABELA 1. Resumo da análise de variância das folhas de $P$. barbatus e $P$. ornatus (TA= teor de água (\%); $M F=$ massa fresca $(\mathrm{g})$; $\mathrm{MS}=$ massa seca $(\mathrm{g})$.

\begin{tabular}{l|l|l|l|l}
\hline FV & GL & \multicolumn{3}{|c}{ QUADR ADOS MÉDIOS } \\
& & \multicolumn{1}{|c}{ TA } & \multicolumn{1}{c}{ MS } \\
\hline TRAT & 7 & $52,1015^{*}$ & $0,0374^{*}$ & $0,1401^{*}$ \\
RESID & 24 & 1,6405 & 0,0135 & 0,0048 \\
\hline \multicolumn{2}{c|}{ CV (\%) } & 1,421 & 2,261 & 13,665 \\
\hline
\end{tabular}

*significante ao nível de $5 \%$ de probabilidade pelo teste $\mathrm{F}$.

TABELA2: Comparações entre médias dos teores de massa fresca (MF), massa seca (MS) em gramas e teor de água (TA\%) nos tratamentos de secagem $(\mathrm{PB}=P$. barbatus; $\mathrm{PO}=P$. ornatus; $\mathrm{ECO}=$ estufa convencional; $\mathrm{EVF}=$ estufa de ventilação forçada; $\mathrm{CD}=$ camada delgada; $\mathrm{MCO}=$ microondas).

\begin{tabular}{|c|c|c|c|}
\hline \multirow[t]{2}{*}{ TRATAMENTOS } & \multicolumn{3}{|c|}{ MÉDIAS } \\
\hline & MF & MS & TA \\
\hline PB-ECO & $5,0844 \mathrm{AB}$ & 0,5926 BC & $88,3421 \mathrm{C}$ \\
\hline PB-EVF & $5,2274 \mathrm{AB}$ & 0,5825 BC & 88,8749 BC \\
\hline PB-CD & $5,3425 \mathbf{A}$ & $0,6930 \mathrm{AB}$ & $87,0390 \mathrm{CD}$ \\
\hline PB-MCO & 5,0553 B & $0,7557 \mathbf{A}$ & 85,0466 D \\
\hline PO-ECO & $5,1134 \mathrm{AB}$ & 0,2492 D & $95,1261 \mathrm{~A}$ \\
\hline PO-EVF & $5,1075 \mathrm{AB}$ & 0,2553 D & $95,0073 \mathrm{~A}$ \\
\hline PO-CD & $5,1300 \mathrm{AB}$ & $0,4300 \mathrm{C}$ & 91,6216 B \\
\hline PO-MCO & $5,0711 \mathrm{AB}$ & $0,5105 \mathrm{C}$ & 89,9367 BC \\
\hline
\end{tabular}

As médias seguidas de uma mesma letra não variaram estatisticamente pelo teste de Tukey a $5 \%$ de significância. 
consequentemente ocorrerá menor perda de princípio ativo.

método gravimétrico com menor perda de água tanto em PB quanto em $\mathrm{PO}$ foi $\mathrm{MCO}$, com as menores médias de TA (Tabela 2). Este método de secagem é o que causa mais danos em folhas das espécies em estudo por ser secagem rápida; o que facilitaria a volatilização de compostos que são relevantes na manutenção das propriedades medicinais dos boldos.

A média geral dos rendimentos dos extratos etanólicos foi $15,99 \pm 11,20 \mathrm{~g}$. A variância das médias denota o fato do rendimento entre os extratos serem em função da massa seca obtida, onde obteve-se extratos, por conseguinte, com rendimento de $3 \%$ a $41 \%$. Observa-se que o maior rendimento do extrato seco em $P B$ foi na secagem em $C D$, enquanto que para $\mathrm{PO}$ foi em ECO. Tanto quanto em PB quanto em $\mathrm{PO}$ os extratos de folhas frescas (FRE) tiveram os menores rendimentos. A correlação entre o método de secagem e rendimento do extrato não foi estabelecida, podendo-se inferir a superioridade dos processos artificiais na manutenção da qualidade póscolheita de folhas de boldos brasileiros.

Assim, conclui-se que o método de secagem mais indicado, para as espécies estudadas foi em EVF, por causar menores danos às folhas e ter menor influência sobre a degradação os princípios secundários. Nota-se que não há relação entre o rendimento dos extratos secos o método gravimétrico. $O$ cálculo do rendimento de extratos é fundamental no cultivo e colheita de plantas medicinais, pois, implicará diretamente na massa fresca necessária para obter-se, por dado processo de secagem, determinado teor de extrato, com redução das estimativas de custo e menor perda na cadeia produtiva de plantas medicinais e fitoterápicos.

\section{AGRADECIMENTO \\ À Universidade Federal de Ouro Preto e à FAPEMIG pelas bolsas concedidas.}

\section{REFERÊNCIA}

ABDEL-MOGIB, M; ALBAR, H.A.; BATTERJEE, S.M. Chemistry of the genus Plectranthus. Molecules, v.7, n.1, p.271-301, 2002. AGÊNCIA NACIONAL DE VIGILÂNCIA SANITÁRIA. Farmacopéia Brasileira. Brasília: ANVISA, 2010. 546p. CORRÊA, A.D.; BATISTA, R.S.; QUINTAS, L.E.M. Plantas Medicinais: do cultivo à terapêutica. Petrópolis: Vozes, 1998. 245p.

DELLAR, J.E.; COLE, M.D.; WATERMAN, P.G. Antimicrobial abietane diterpenoids from Plectranthus elegans. Phytochemistry, v.41, n.1, p.735-738, 1996.

DUBEY, M.P.; SRIMAL, R.C.; NITYANAND, S. et al. Pharmacological studies on coleonol, a hypotensive diterpene from Coleus forskohlii. Journal of Ethnopharmacology, v.3, n.1, p.1-13, 1981.

LORENZI, H.; MATOS, F.J.A. Plantas Medicinais no Brasil: Nativas e Exóticas. Nova Odessa (SP): Instituto Plantarum, 2008. 544p.

LUKHOBA, C.W.; SIMMONDS, M.S.J.; PATON, A.J. Plectranthus: a review of ethnobotanical uses. Journal of Ethnopharmacolgy, v.103, n.1, p.1-24, 2006.

SAEG. Sistema para análises estatísticas. Viçosa: Universidade Federal de Viçosa, 2010. Versão 9.1. Disponível em: <http://www.ufv.br>. Acesso em: 29 de maio de 2011.

YANG, Q.R.; WU, H.Z.; WANG, X.M. et al. Three new diterpenoids from Coleus forskohlii Briq. Journal Asiatic of Natural Product Research, v.8, n.4, p.355-360, 2006. 